\title{
Effects of adipose tissue-derived stromal vascular fraction on osteochondral defects treated by hyaluronic acid-based scaffold: An experimental study
}

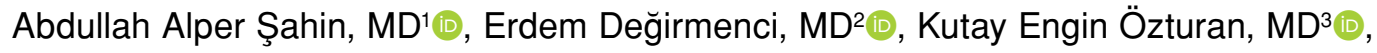 \\ Tülin Fırat, $M^{4}{ }^{4}$, Aysel Kükner, $M^{5}{ }^{5}$ \\ ${ }^{1}$ Department of Orthopedics and Traumatology, Ordu University Training and Research Hospital, Ordu, Turkey \\ ${ }^{2}$ Department of Orthopedics and Traumatology, Private Cagsu Hospital, Düzce, Turkey \\ ${ }^{3}$ Department of Orthopedics and Traumatology, AIBU Izzet Baysal Training and Research Hospital, Bolu, Turkey \\ ${ }^{4}$ Department of Histology and Embryology, AIBU Izzet Baysal Training and Research Hospital, Bolu, Turkey \\ ${ }^{5}$ Department of Histology and Embryology, Near East University, Lefkoşa, Turkish Republic of Northern Cyprus
}

Osteochondral lesions are frequently observed in the field of orthopedics, and caused by an acute or repetitive traumatic event. ${ }^{[1]}$ The damage of articular cartilage can cause pain, effusion, osteoarthritis, and joint dysfunction. Articular cartilage defects have a limited intrinsic regeneration capacity, due to its inherent avascular, aneural, alymphatic, and having a low cellularity. ${ }^{[2]}$ Even if a limited repair is achieved with conventional methods in the treatment of osteochondral lesions, it still poses many difficulties today. In general, the healing process results in the formation of fibrous cartilage that does not possess the same biomechanical features as the original hyaline tissue. ${ }^{[3,4]}$ Many methods have been attempted

Received: February 22, 2021

Accepted: May 03, 2021

Published online: June 11, 2021

Correspondence: Abdullah Alper Şahin, MD. Ordu Üniversitesi Eğitim ve Araştırma Hastanesi Ortopedi ve Travmatoloji Kliniği, 52200 Altınordu, Ordu, Türkiye.

E-mail: dr.a.alpersahin@gmail.com

Doi: $10.52312 /$ jdrs.2021.19

Citation: Şahin AA, Değirmenci E, Özturan KE, Fırat T, Kükner A. Effects of adipose tissue-derived stromal vascular fraction on osteochondral defects treated by hyaluronic acid-based scaffold: An experimentalstudy. JtDis RelatSurg 2021;32(2):347-354.

(2021 All right reserved by the Turkish Joint Diseases Foundation

This is an open access article under the terms of the Creative Commons Attribution-NonCommercial License, which permits use, distribution and reproduction in any medium, provided the original work is properly cited and is not used for commercial purposes (http://creativecommons.org/licenses/by-nc/4.0/)

\section{ABSTRACT}

Objectives: This study aims to evaluate the effect of adipose-derived stromal vascular fraction (SVF) on osteochondral defects treated by hyaluronic acid (HA)-based scaffold in a rabbit model.

Materials and methods: Eighteen white New Zealand rabbits were randomly grouped into the experimental group $(n=9)$ and control group $(n=9)$. In all groups, osteochondral defects were induced on the weight-bearing surfaces of the right femoral medial condyles, and a HA-based scaffold was applied to the defect area with microfractures (MFs). In this study, $1 \mathrm{~mL}$ of adipose-derived SVF was injected into the knee joints of the rabbits in the experimental group. For histological and macroscopic evaluation, four rabbits were randomly selected from each group at Week 4 , and the remaining rabbits were sacrificed at the end of Week 8. Macroscopic assessments of all samples were performed based on the Brittberg scoring system, and microscopic evaluations were performed based on the O’Driscoll scores.

Results: Samples were taken at Weeks 4 and 8. At Week 4, the O'Driscoll scores were significantly higher in the control group than the experimental group $(\mathrm{p}=0.038)$, while there was no significant difference in the Brittberg scores between the two groups $(\mathrm{p}=0.108)$. At Week 8, the O'Driscoll score and Brittberg scores were statistically higher in the experimental group than in the control group ( $\mathrm{p}=0.008$ and $\mathrm{p}=0.007$, respectively). According to the microscopic evaluation, at the end of Week 8, the cartilage thickness was greater in the experimental group, and nearly all of the defect area was filled with hyaline cartilage. Conclusion: Application of adipose-derived SVF with MF-HA-based scaffold was better than MF-HA-based scaffold treatment in improving osteochondral regeneration. Therefore, it can be used in combination with microfracture and scaffold to accelerate cartilage regeneration, particularly in the treatment of secondary osteoarthritis.

Keywords: Acellular matrix scaffold, adipose tissue, osteochondral defect, stem cell, stromal vascular fraction. 
to accelerate the regeneration of cartilage and to increase the hyaline cartilage rate in the damaged area.

Establishing a therapy that alleviates symptoms of cartilage damage, sustainably halts disease progression, and reverses chondral tissue damage is one of the key challenges in clinical research. ${ }^{[5]}$ The limited healing potential of cartilage tissue has brought stem cell therapies to the forefront. Recent studies have shown that autologous mesenchymal stem cells (MSCs) can differentiate into cartilage and bone in osteochondral lesions. ${ }^{[6]}$ The MSCs are found in many human tissues, particularly in bone marrow and adipose tissue. ${ }^{[7]}$

Stromal vascular fraction (SVF) factors derived from adipose tissue lipoaspirates refer to stromal tissues containing various stem cells, as well as other supporting cells and signaling molecules. ${ }^{[8]}$ The MSCs derived from adipose tissue in SVF secrete various anti-inflammatory agents such as interleukin-1 receptor antagonist, nitric oxide, transforming growth factor (TGF) 1, and stromal cell-derived factor 1 . Thus, they alleviate joint inflammation..$^{[9]}$ The immunomodulatory effect of SVF, in particular, is promising for the regenerative treatment of osteoarthritis. ${ }^{[10]}$ However, whether SVF contributes to the regeneration of cartilage tissue in the injected joints has not yet been fully elucidated. Although some studies have reported a significant cartilage regeneration, ${ }^{[11,12]}$ others have not observed changes. ${ }^{[13]}$

In joint areas where there is little blood supply, scaffolds can be used to increase the attachment of cells to the damaged area. In addition, scaffolds stimulate the proliferation and differentiation of stem cells. ${ }^{[14]}$ However, scaffolds should be biocompatible and biodegradable, should allow cell attachment and interaction, and should have suitable porosity. ${ }^{[15]}$ In our study, we used hyaluronic acid (HA)-based acellular matrix scaffold to increase the adhesion, proliferation, and differentiation of stem cells to the defect area in the treatment of osteochondral defects. In the present study, we hypothesized that adipose-derived SVF could enhance the healing and regeneration of osteochondral defects treated with a combination of microfractures (MFs) and HA-based scaffold. We aimed to investigate whether adipose-derived SVF increased HA-based scaffold efficiency.

\section{MATERIALS AND METHODS}

This study was conducted with the approval of the Animal Research Ethics Committee of Abant Izzet
Baysal University (No: 12.04.2017/16). The European laws on animal experimentation were strictly followed throughout the study. The animal experimental protocol was devised as per Turkey Law according to EC rules (Law by Decree, 2010/63/EU).

In this study, we used a popular method for studying cartilage repair techniques using biomaterials in experimental animals to create a defect in femoral condyles and trochlea. Rabbits represent a species that is extremely suitable for testing new biomaterials or new treatments, as they are relatively inexpensive and offer a good joint size for surgical procedures. ${ }^{[16]}$ White New Zealand rabbits are suitable for the endurance tests of the traditional regulatory committee and recommended in the ISO 10993 guidelines. In this study, 18 rabbits weighing $2500 \mathrm{~g}$ (age $>4$ months) were procured from the Abant Izzet Baysal University Experimental Animal Care Center. The rabbits were randomly grouped into the experimental group $(n=9)$ and control group $(n=9)$. All animals were kept in light and dark with a relative humidity of 40 to $60 \%$ at a mean temperature of $20 \pm 3^{\circ} \mathrm{C}$ and a photoperiod of $12 / 12 \mathrm{~h}$. Each rabbit was placed in a stainless-steel cage with a bottom grid. The animals were fed on a pellet diet and had an access to tap water ad libitum.

The Lipogems ${ }^{\circledR}$ (Lipogems International SpA, Milan, Italy) is a simple system designed to collect, process, and transfer the refined adipose tissues. Using this technology, the adipose tissue is split into micro-fragments and purified from proinflammatory fat and blood residues without enzymes or other additives. This resulting product contains pericides and readily interacts with the receiving tissue following transplantation; thus, it is activated as MSCs. ${ }^{[17]}$ This system works through a slight reduction in the size of a mechanical set of tissues in a completely closed system without the use of any enzymes and additives. ${ }^{[18]}$

The Hyalofast ${ }^{\circledR}$ comprises a single threedimensional fibrous Hyaff ${ }^{\circledR}$ (Fidia Advanced Biopolymers, Abano Terme, Italy) layer, a benzyl ester of HA, which is a natural component of the extracellular matrix. It can be cut and adjusted to irregular lesions given by its soft and nonwoven structure. The Hyalofast ${ }^{\circledR}$ can be implanted by mini-arthrotomy or arthroscopic surgery. Once implanted, it retains its structure, which promotes binding, proliferation and differentiation of MSCs to completely fill the lesion. As the Hyaff ${ }^{\circledast}$ degrades over time, it releases HA into the lesion area and creates an embryonic-like microenvironment rich in HA. ${ }^{[19]}$ 


\section{Surgical procedure}

The right knees of all animals were treated. The hair on the surgical area of the right knees was shaved. The area was cleaned with povidone-iodine and covered with a surgical drape. After the skin incision, a $3-\mathrm{cm}$ medial parapatellar incision was created, and the patella was everted. Osteochondral defects with a width of $4 \mathrm{~mm}$ and a depth of $5 \mathrm{~mm}$ were induced on the weight-bearing surfaces of the medial condyle using a sleeve-controlled drill. The critical size of a chondral defect in a rabbit knee was previously defined as $3 \mathrm{~mm}$ to prevent spontaneous healing. ${ }^{[20]}$ A $1.5-\mathrm{mm}$ Kirschner wire was used to induce MF on all defects. The MF was performed from exactly the center of the defect, and leakage of blood and adipose tissue from the medulla was observed. Consequently, 18 cylindrical osteochondral defects were induced on the condyles. Clot transposition from the subchondral tissue to the lesion site was observed, and the HA-based scaffold (Hyalofast ${ }^{\circledR}$ ) with the same size was cut and placed on the defect. After the closure of the joint capsule, percutaneous adipose tissue aspirate was obtained from under the skin in the abdominal region of the rabbits in the experimental group. The adipose tissue aspirate was, then, mechanically processed to obtain adipose-derived SVF using an innovative technique (Lipogems ${ }^{\circledR}$ ). The experimental group was injected with a single dose of $1 \mathrm{~mL}$ of adipose-derived SVF into the knee joints, and $1 \mathrm{~mL}$ of saline was administered intraarticularly to the control group. All surgical procedures were performed under anesthesia and sterile conditions by an orthopedic surgeon with at least five years of experience. For anesthetic induction, ketamine (Ketavet ${ }^{\circledR}$, Farmaceutici Gellini, Italy) and xylazine (Rompun ${ }^{\circledR}$, Bayer, Leverkusen, Germany) were administered by intramuscular injection.

All animals were administered antibiotic prophylaxis intramuscularly with a single dose of cephalosporin sodium (20 mg/ $\mathrm{kg}$, Iespor $^{\circledR}$, Ibrahim Etem Ulagay, Istanbul, Turkey). Ekici et al. ${ }^{[2]}$ demonstrated that no significant histopathological damage in the cartilage after intraarticular administration of dexketoprofen trometamol. Analgesia was achieved using dexketoprofen trometamol (Arveles ${ }^{\circledR}$, Menarini, Italy), intramuscularly. After surgery, the rabbits were kept in small cages for two weeks and, after the knee joints were immobilized for 10 days with a splint, they were allowed to move freely. All animals randomly selected from the control and experimental groups and they were sacrificed at
Weeks $4(\mathrm{n}=8)$ and $8(\mathrm{n}=10)$ after surgery using high-strength ether to facilitate removal of medial condyles for histological examination.

\section{Histological analysis and histomorphometric analysis}

Macroscopic examination of the implantation site was performed by observation of the tissue appearance and by photographic documentation. Any abnormalities in the repair zone were recorded with details of the location, color, shape and size, and grading was performed by using the Brittberg scoring. The Brittberg score is a macroscopic scoring system that evaluates the quality of defect repair tissue and its integration with surrounding cartilage, as well as the macroscopic appearance. Each part of this evaluation can score 0 to 4 points. The repair is, then, classified as Grade I (normal repair, 12 points), Grade II (near-normal, 8 to 11 points), Grade III (abnormal, 4 to 7 points), or Grade IV (severely abnormal, 0 to 3 points). ${ }^{[22,23]}$ From each implanted knee, tissue samples from the area of implantation were collected for hematoxylin-eosin and Masson's trichrome staining. The histological assessment of the procedure site was performed by using the O'Driscoll scores. ${ }^{[24]}$ The sections were scored by two pathologists blinded to the
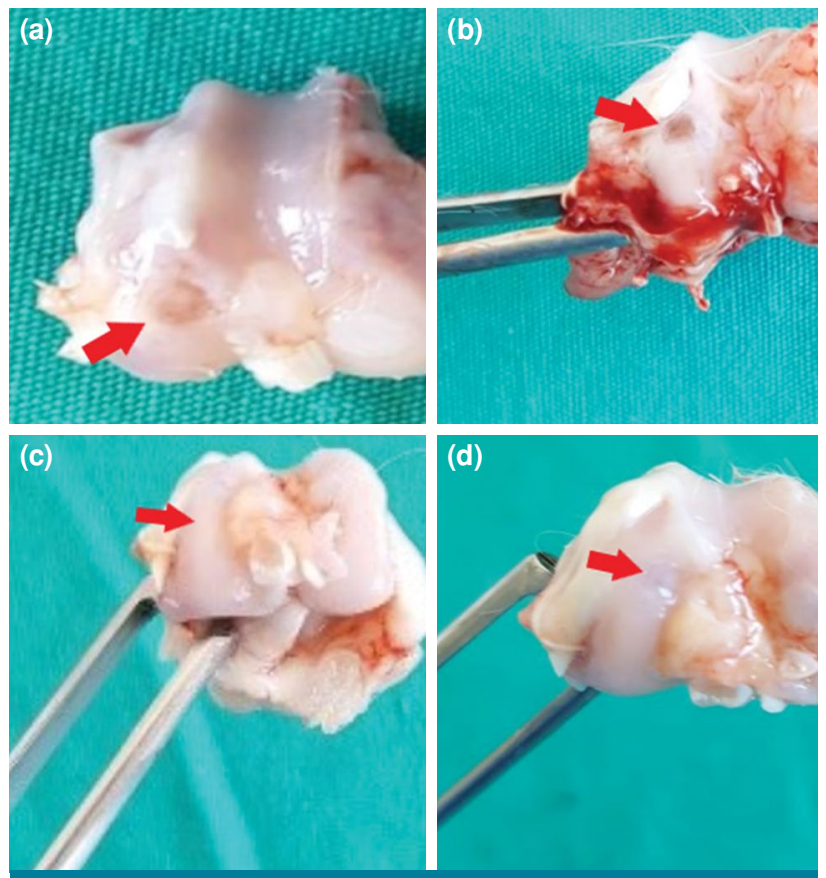

FIGURE 1. (a) A macroscopic view of experimental group at Week 4. (b) A macroscopic view of control group at Week 4. (c) A macroscopic view of experimental group at Week 8. (d) A macroscopic view of control group at Week 8. 


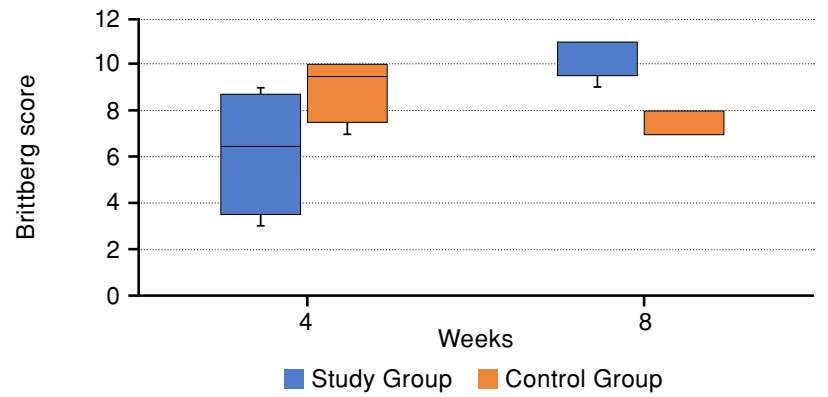

FIGURE 2. Macroscopic scoring of the groups (Brittberg score). The box represents $50 \%$ of the sample. Single line inside the box represents median values. Cross mark inside the box represents mean values.

study groups. The samples were scored according to the modification of the histological grading scale described by O'Driscoll et al. ${ }^{[24]}$ This grading comprises five categories: cell morphology, matrix staining, surface regularity, cartilage thickness, and binding. The total score ranges from 0 to 16 . Grading was performed at $100 \times$ magnification. All samples were evaluated by a LEICA DM LB2 light microscope (Leica Microsystems Wetzlar GmbH, Wetzlar, Germany) and photographed with the INFINITY 3
ANALYZE Release 6.5 imaging system (Lumenera Inc., Ottawa, ON, Canada).

\section{Statistical analysis}

Statistical analysis was performed using the IBM SPSS version 22.0 software (IBM Corp., Armonk, NY, USA). Descriptive data were expressed in mean \pm standard deviation (SD) or median (min-max). The Mann-Whitney U test was used to compare the groups and condyle effects together at each time point. A $p$ value of 0.05 was considered statistically significant.

\section{RESULTS}

In total, 18 animals were analyzed in the study, and no wound infection or death was observed. In the first seven days, mild edema and swelling were observed in the knee joint areas of all subjects. During sacrifice, all defect areas could be distinguished macroscopically from the surrounding cartilage tissues, and no synovitis or infective tissue was detected in the surgical area.

Macroscopic examination of tissue samples taken at Week 4 according to the Brittberg scoring revealed that the lesion groups were filled with
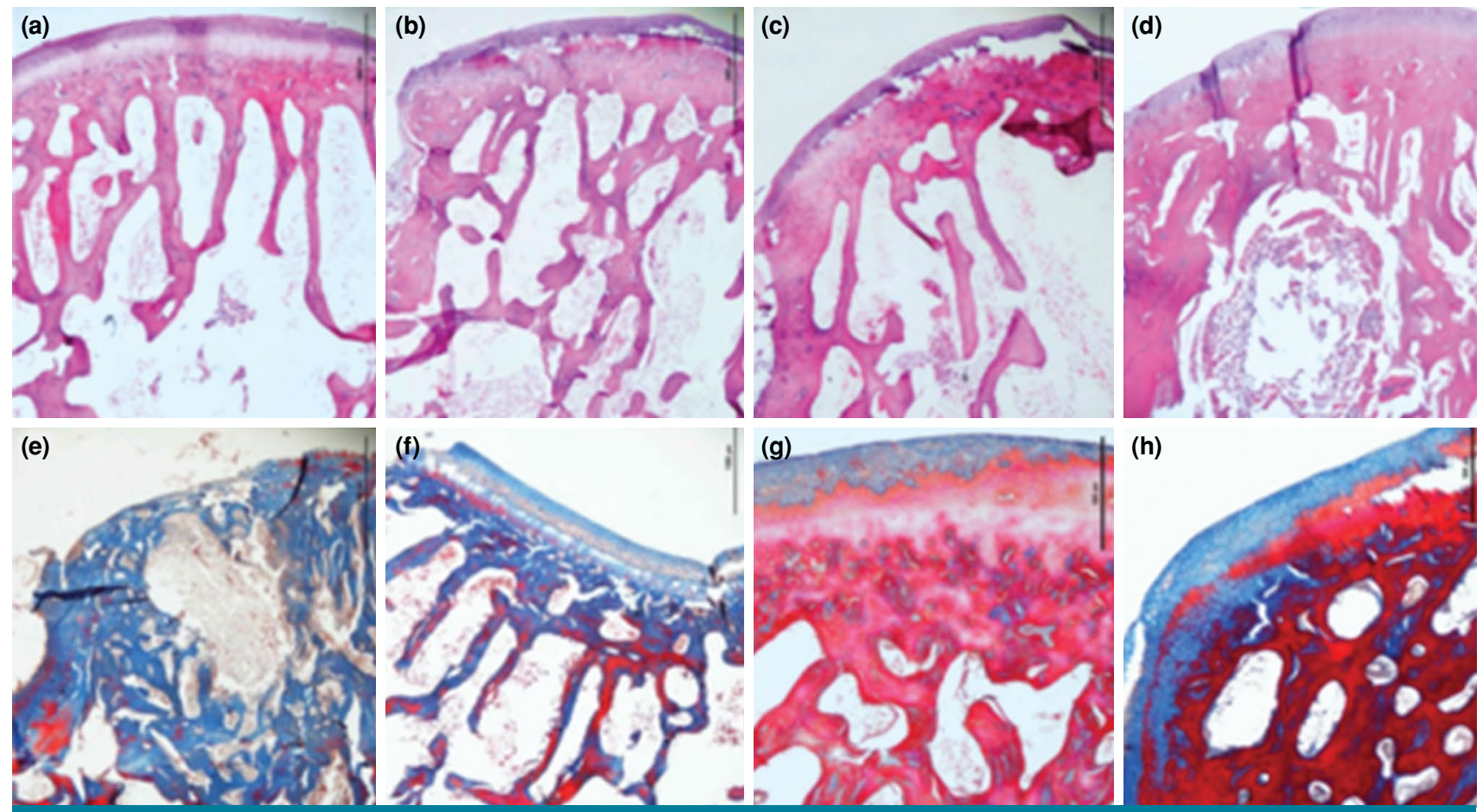

FIGURE 3. Microscopic views of the samples (H-E, $\times 40$ : a, b, c, d; Masson trichrome, $\times 4$ : e, f, g, h). (a, e) A microscopic view of control group at Week 4. (b, f) A microscopic view of experimental group at Week 4. (c, g) A microscopic view of control group at Week 8. (d, h) A microscopic view of experimental group at Week 8. 
repair tissue. At Week 4, a near-normal (Grade II) improvement was observed in the two samples taken from the experimental group, while three samples from the control group showed a nearnormal improvement. In the experimental group, a severely abnormal repair (Grade IV) was observed in one sample, while the other sample was repaired at an abnormal level (Grade III). Grade III repair was detected in the other sample from the control group. At Week 8, a near-normal improvement was seen in all samples from the experimental group, while two samples from the experimental group had Grade II and three samples showed Grade III improvement (Figures 1 and 2).

At Week 4, macroscopic improvement in the medial condyles was higher in the control group than the experimental group, although it was not statistically significant $(\mathrm{p}=0.108)$. Macroscopic improvement at Week 8 was significantly higher in medial condyles in the experimental group than the control group $(\mathrm{p}=0.007)$.

Histologically, the ratio of hyaline cartilage in the subchondral tissue regeneration area in the control group was higher than that in the experimental group at Week 4. At Week 8, the rate of cartilage tissue repair and hyaline cartilage tissue ratio was higher in the experimental group than the control group. While no significant difference was found between the groups in terms of surface regularity at Week 8 , the resulting cartilage thickness was near-complete in the experimental group (Figure 3, Table I).

At Week 4, a histological improvement in the medial condyles was significantly higher in the control group than the experimental group $(\mathrm{p}=0.038)$. Histological improvement at Week 8 was significantly higher in medial condyles in the experimental group than the control group $(\mathrm{p}=0.008)$ (Table II).

\begin{tabular}{|c|c|c|c|c|c|}
\hline \multicolumn{6}{|c|}{$\begin{array}{c}\text { TABLE I } \\
\text { ogical scale which graded cartilage samples }\end{array}$} \\
\hline \multirow{3}{*}{ Score } & & \multicolumn{2}{|c|}{ Fourth Week } & \multicolumn{2}{|c|}{ Eighth week } \\
\hline & & Experimental Group & Control Group & Experimental Group & Control Group \\
\hline & $\mathrm{n}$ & $\mathrm{n}$ & $\mathrm{n}$ & $\bar{n}$ & $\mathrm{n}$ \\
\hline \multicolumn{6}{|l|}{ Cell morphology } \\
\hline Hyaline cartilage & 4 & & & 3 & \\
\hline Mostly hyaline cartilage & 3 & & 1 & 2 & 3 \\
\hline Hyaline and fibrocartilage & 2 & 2 & 3 & & 1 \\
\hline Mostly fibrocartilage & 1 & 2 & & & 1 \\
\hline Mostly non-cartilage & 0 & & & & \\
\hline \multicolumn{6}{|l|}{ Matrix staining } \\
\hline Same as the normal area & 4 & & & 4 & \\
\hline Slightly reduced & 3 & 2 & 2 & 1 & 3 \\
\hline Reduced & 2 & 1 & 2 & & 2 \\
\hline Significantly reduced & 1 & 1 & & & \\
\hline None & 0 & & & & \\
\hline \multicolumn{6}{|l|}{ Surface regularity } \\
\hline Smooth & 2 & & 3 & 4 & 4 \\
\hline Slightly irregular & 1 & 1 & 1 & 1 & 1 \\
\hline Irregular & 0 & 3 & & & \\
\hline \multicolumn{6}{|l|}{ Thickness of the cartilage (\%) } \\
\hline 100 & 4 & 1 & 2 & 5 & \\
\hline 75 & 3 & 1 & 2 & & 3 \\
\hline 50 & 2 & 1 & & & 2 \\
\hline 25 & 1 & 1 & & & \\
\hline 0 & 0 & & & & \\
\hline \multicolumn{6}{|l|}{ Bonding } \\
\hline Both edges integrated & 2 & 2 & 4 & 5 & 5 \\
\hline One edge integrated & 1 & 1 & & & \\
\hline Both edges not integrated & 0 & 1 & & & \\
\hline
\end{tabular}




\begin{tabular}{|c|c|c|c|c|c|c|c|}
\hline & & Mean and & $\begin{array}{r}\text { TABL } \\
\text { ian O'Driscol }\end{array}$ & res of the ty & ups & & \\
\hline & & rimental $C$ & & & ntrol Gro & & \\
\hline & Mean $\pm S D$ & Median & Min-Max & Mean $\pm S D$ & Median & Min-Max & $p^{*}$ \\
\hline Fourth week & $7.75 \pm 3.40$ & 8.50 & $3.00-11.00$ & $12.25 \pm 1.50$ & 12.00 & $11.00-14.00$ & 0.038 \\
\hline Eighth week & $15.20 \pm 0.84$ & 15.00 & $14.00-16.00$ & $11.40 \pm 2.30$ & 13.00 & $8.00-13.00$ & 0.008 \\
\hline
\end{tabular}

\section{DISCUSSION}

As the most important finding in our study, adipose tissue-derived SVF injection increased the effectiveness of the combination of HA-based scaffold and MF. In addition, adipose tissue-derived SVF treatment increased the hyaline cartilage formation and cartilage thickness in osteochondral defects.

Although researches have established the ability of MSCs obtained from different tissues to produce cartilage, bone marrow and adipose tissues are considered the most important sources for the therapeutic use of MSCs in cartilage regeneration. ${ }^{[6,25,26]}$ Nishimori et al. ${ }^{[27]}$ used bone marrow-derived MSCs in the treatment of osteochondral defects and showed that histological scores were significantly better in the bone marrow mesenchymal stromal cell group than in other groups at all time points. Zhu et al. ${ }^{[28]}$ also used a combination of bone marrow-derived MSCs and connective tissue growth factor in the treatment of cartilage damage and showed that the regenerated hyaline cartilage that was formed was similar to the normal hyaline cartilage. Another study showed that adipose-derived stem cells (ADSCs) were more stable than bone marrow MSCs and ADSCs were implicated as being a better cell source for osteoarthritis treatment. ${ }^{[29]}$ In our study, we obtained adipose-derived-SVF using adipose tissues from the abdominal region of rabbits. As the main advantages, our method enabled harvesting of MSCs in a minimally invasive manner and, then, isolation and the time-consuming in vitro cell culture is not required, ultimately.

In the literature, adipose tissue-derived MSCs have been used in the treatment of osteochondral defects, except for bone marrow-derived MSCs. Fodor and Paulseth ${ }^{[30]}$ used adipose-derived-SVF from the enzymatic degradation of lipoaspirate in osteoarthritic knees and showed that autologous SVF was safe and reduced pain in knee osteoarthritis. In this study, clinical pain relief was detected in all patients, although no significant difference was found radiologically. One of the advantages of our procedure is that enzymatic degradation is not required and it is not time-consuming. Additionally, we evaluated the histopathological effects of adiposederived-SVF and obtained statistically significant results.

In their study, Ceylan et al. ${ }^{[13]}$ compared MF and combination of MF and adipose-derived MSCs in chondral healing. In this study, MF alone did not demonstrate a significant superiority to the combination treatment after Week 8. In our study, we compared MF-scaffold combination with MF-scaffoldadipose-derived SVF combination. The groups were evaluated at Weeks 4 and 8 as early and late periods, respectively. We found a histologically significant difference in the MF-scaffold group at Week 4. On the other hand, at Week 8, we found a significant improvement in the MF-scaffold-oil-derived SVF group both microscopically and macroscopically.

The scaffold is a three-dimensional structure that can support cell colonization, proliferation, and differentiation of suitable cells. Both synthetic and natural scaffold types have been used as tools for cartilage engineering in the literature ${ }^{[31,32]}$ Among these scaffolds, bioavailable and biologically absorbable HA-based scaffolds, which have a suitable chemical structure for covalent binding of chondrocytes, are the most suitable implants. They also facilitate the production of collagen (Types 1 and 2) from MSC via TGF, which enhances chondrogenic recovery. ${ }^{[33]}$ Oshima et al. ${ }^{[34]}$ investigated the histological effects of three-dimensional scaffold-free allogeneic ADSCs implanted on osteochondral defects in a rabbit model. Although they could not find a significant difference in histological scoring between the control and experimental groups at Week 4, there was a significantly higher histological score in the experimental group at Weeks 8 and 12. In our study, we observed a histologically significant difference at Week 4 in the control group, while the histological and macroscopic scoring was significantly higher in the experimental group at Week 8. Yontar et 
al. ${ }^{[35]}$ applied MF-HA-based scaffold combination in the treatment of talus osteochondral defect and concluded that it was a safe and effective technique with good clinical results for lesions deeper than $7 \mathrm{~mm}$. In our study, adipose-derived SVF increased the efficacy of MF-HA-based scaffold combination used in osteochondral treatment, particularly in the late period, and we were able to show this effect macroscopically and histologically.

In our study, more stable cartilage formation was observed in MF-HA-based scaffold-SVF combination compared to the MF-HA-based scaffold treatment in both microscopic and macroscopic evaluations at Week 8 . The macroscopic results of our study revealed that the regularity of the surface was smoother and the integration with the surrounding cartilage was greater, with higher average Brittberg scores in the experimental group than the control group at Week 8 . In addition, microscopic examinations indicated that subchondral tissue and cartilage tissue regeneration was more organized and hyaline cartilage ratio was higher than the control group.

Nonetheless, this study is limited by the size of the osteochondral defect $(4 \mathrm{~mm})$, since creating a larger osteochondral defect could prevent healing. Therefore, we cannot clearly predict large osteochondral injuries that can occur in the knee. Our study showed an effect on the healing of acute osteochondral defects and, therefore, we cannot comment on chronic lesions. In addition, we used saline to reduce the effect of heat damage while creating an osteochondral defect; however, a custommade cylindrical chondrotome could be used to completely eliminate the heat effect. In this study, the thigh cartilage surface of the rabbit was selected to create a cartilage defect, as it resembles humans and provides easy access for surgery. Although additional time may be needed for chondral healing, we terminated the experiment in the eighth week based on the general practice in the literature (between six and 12 weeks). Long-term studies may be carried out to observe long-term changes. In addition, we could not determine any significant difference between the groups at Week 4 which may be due to the low number of animals at this time point. Therefore, it may be necessary to work with a large sample group. The study had an experimental design and, thus, we were unable to make comparisons in terms of clinical and functional outcomes. In our study, specific immunohistochemical staining could have been additionally performed to determine the type of collagen formed in the regeneration zone of cartilage damage. However, findings are limited to rabbits and must be confirmed in human clinical studies. In addition, our study could be supported by imaging methods.

In conclusion, our study results showed that adipose-derived SVF enhanced the healing of osteochondral defects treated with MF and HA-based scaffolds. Also, adipose tissue-derived SVF treatment increased hyaline cartilage formation and cartilage thickness in osteochondral defects. Therefore, the results of our study suggest that adipose-derived SVF increases regeneration of osteochondral defects treated with MF and HA-based scaffolds. However, we believe that long-term experimental studies are required to evaluate the long-term effects of adipose tissue-derived SVF and further large-scale studies can yield more accurate results.

\section{Declaration of conflicting interests}

The authors declared no conflicts of interest with respect to the authorship and/or publication of this article.

\section{Funding}

The authors received no financial support for the research and/or authorship of this article.

\section{REFERENCES}

1. Eren TK, Ataoğlu MB, Eren A, Geylan DE, Öner AY, Kanatlı U. Comparison of arthroscopic microfracture and cell-free scaffold implantation techniques in the treatment of talar osteochondral lesions. Eklem Hastalik Cerrahisi 2019;30:97-105.

2. Hangody L, Dobos J, Baló E, Pánics G, Hangody LR, Berkes I. Clinical experiences with autologous osteochondral mosaicplasty in an athletic population: A 17-year prospective multicenter study. Am J Sports Med 2010;38:1125-33.

3. Korucu İH, Kekeç AF, Arslan A, Oltulu P, Korucu EN, Özer $M$. Regenerative effects of hyperbaric oxygen therapy and platelet-rich plasma on the osteochondral defects of rats. Jt Dis Relat Surg 2020;31:260-6.

4. Sezgin EA, Atik OŞ. Are orthobiologics the next chapter in clinical orthopedics? A literature review. Eklem Hastalik Cerrahisi 2018;29:110-6.

5. Simunec D, Salari H, Meyer J. Treatment of grade 3 and 4 osteoarthritis with intraoperatively separated adipose tissue-derived stromal vascular fraction: A comparative case series. Cells 2020;9:2096.

6. Diekman BO, Rowland CR, Lennon DP, Caplan AI, Guilak F. Chondrogenesis of adult stem cells from adipose tissue and bone marrow: Induction by growth factors and cartilage-derived matrix. Tissue Eng Part A 2010;16:523-33.

7. Murray IR, West CC, Hardy WR, James AW, Park TS, Nguyen A, et al. Natural history of mesenchymal stem cells, from vessel walls to culture vessels. Cell Mol Life Sci 2014;71:1353-74.

8. Lander EB, Berman MH. Autologous stromal vascular fraction: A new era of personal cell therapy. J Stem Cell Res Dev Ther 2018;4:1-6. 
9. Dimarino AM, Caplan AI, Bonfield TL. Mesenchymal stem cells in tissue repair. Front Immunol 2013;4:201.

10. Bowles AC, Wise RM, Gerstein BY, Thomas RC, Ogelman $\mathrm{R}$, Febbo I, et al. Immunomodulatory effects of adipose stromal vascular fraction cells promote alternative activation macrophages to repair tissue damage. Stem Cells 2017;35:2198-207.

11. Nguyen PD, Tran TD, Nguyen HT, Vu HT, Le PT, Phan NL, et al. Comparative clinical observation of arthroscopic microfracture in the presence and absence of a stromal vascular fraction injection for osteoarthritis. Stem Cells Transl Med 2017;6:187-95.

12. Tran TDX, Wu CM, Dubey NK, Deng YH, Su CW, Pham $\mathrm{TT}$, et al. Time- and Kellgren-Lawrence grade-dependent changes in intra-articularly transplanted stromal vascular fraction in osteoarthritic patients. Cells 2019;8:308.

13. Ceylan $\mathrm{HH}$, Bilsel K, Buyukpinarbasili N, Ceylan H, Erdil M, Tuncay I, et al. Can chondral healing be improved following microfracture? The effect of adipocyte tissue derived stem cell therapy. Knee 2016;23:442-9.

14. Rios HF, Lin Z, Oh B, Park CH, Giannobile WV. Celland gene-based therapeutic strategies for periodontal regenerative medicine. J Periodontol 2011;82:1223-37.

15. Chaudhari AA, Vig K, Baganizi DR, Sahu R, Dixit S, Dennis $\mathrm{V}$, et al. Future prospects for scaffolding methods and biomaterials in skin tissue engineering: A review. Int J Mol Sci 2016;17:1974.

16. Chu CR, Szczodry M, Bruno S. Animal models for cartilage regeneration and repair. Tissue Eng Part B Rev 2010;16:105-15.

17. Tremolada C, Colombo V, Ventura C. Adipose tissue and mesenchymal stem cells: state of the art and Lipogems ${ }^{\circledR}$ technology development. Curr Stem Cell Rep 2016;2:304-12.

18. Bianchi F, Maioli M, Leonardi E, Olivi E, Pasquinelli G, Valente $S$, et al. A new nonenzymatic method and device to obtain a fat tissue derivative highly enriched in pericytelike elements by mild mechanical forces from human lipoaspirates. Cell Transplant 2013;22:2063-77.

19. Buda R, Vannini F, Cavallo M, Baldassarri M, Luciani D, Mazzotti A, et al. One-step arthroscopic technique for the treatment of osteochondral lesions of the knee with bonemarrow-derived cells: Three years results. Musculoskelet Surg 2013;97:145-51.

20. Meng X, Ziadlou R, Grad S, Alini M, Wen C, Lai Y, et al. Animal models of osteochondral defect for testing biomaterials. Biochem Res Int 2020;2020:9659412.

21. Ekici AG, Akyol O, Ekici M, Sitilci T, Topacoglu H, Ozyuvaci E. Intra-articular injection of dexketoprofen in rat knee joint: Histopathologic assessment of cartilage \& synovium. Indian J Med Res 2014;140:227-30.

22. Brittberg M, Winalski CS. Evaluation of cartilage injuries and repair. J Bone Joint Surg [Am] 2003;85(Suppl 2):58-69.

23. Bauer C, Jeyakumar V, Niculescu-Morzsa E, Kern D, Nehrer S. Hyaluronan thiomer gel/matrix mediated healing of articular cartilage defects in New Zealand White rabbits-a pilot study. J Exp Orthop 2017;4:14.

24. O'Driscoll SW, Keeley FW, Salter RB. Durability of regenerated articular cartilage produced by free autogenous periosteal grafts in major full-thickness defects in joint surfaces under the influence of continuous passive motion. A follow-up report at one year. J Bone Joint Surg [Am] 1988;70:595-606.

25. Dragoo JL, Carlson G, McCormick F, Khan-Farooqi H, Zhu M, Zuk PA, et al. Healing full-thickness cartilage defects using adipose-derived stem cells. Tissue Eng 2007;13:1615-21.

26. Somoza RA, Welter JF, Correa D, Caplan AI. Chondrogenic differentiation of mesenchymal stem cells: Challenges and unfulfilled expectations. Tissue Eng Part B Rev 2014;20:596-608.

27. Nishimori M, Deie M, Kanaya A, Exham H, Adachi N, Ochi M. Repair of chronic osteochondral defects in the rat. A bone marrow-stimulating procedure enhanced by cultured allogenic bone marrow mesenchymal stromal cells. J Bone Joint Surg [Br] 2006;88:1236-44.

28. Zhu S, Zhang B, Man C, Ma Y, Liu X, Hu J. Combined effects of connective tissue growth factor-modified bone marrowderived mesenchymal stem cells and $\mathrm{NaOH}$-treated PLGA scaffolds on the repair of articular cartilage defect in rabbits. Cell Transplant 2014;23:715-27.

29. Zhou W, Lin J, Zhao K, Jin K, He Q, Hu Y, et al. Singlecell profiles and clinically useful properties of human mesenchymal stem cells of adipose and bone marrow origin. Am J Sports Med 2019;47:1722-33.

30. Fodor PB, Paulseth SG. Adipose Derived Stromal Cell (ADSC) injections for pain management of osteoarthritis in the human knee joint. Aesthet Surg J 2016;36:229-36.

31. Dahlin RL, Kinard LA, Lam J, Needham CJ, Lu S, Kasper FK, et al. Articular chondrocytes and mesenchymal stem cells seeded on biodegradable scaffolds for the repair of cartilage in a rat osteochondral defect model. Biomaterials 2014;35:7460-9.

32. Tsai MC, Hung KC, Hung SC, Hsu SH. Evaluation of biodegradable elastic scaffolds made of anionic polyurethane for cartilage tissue engineering. Colloids Surf B Biointerfaces 2015;125:34-44.

33. Chircov C, Grumezescu AM, Bejenaru LE. Hyaluronic acid-based scaffolds for tissue engineering. Rom J Morphol Embryol 2018;59:71-6.

34. Oshima T, Nakase J, Toratani T, Numata H, Takata Y, Nakayama K, et al. A scaffold-free allogeneic construct from adipose-derived stem cells regenerates an osteochondral defect in a rabbit model. Arthroscopy 2019;35:583-93.

35. Yontar NS, Aslan L, Can A, Ogut T. One step treatment of talus osteochondral lesions with microfracture and cell free hyaluronic acid based scaffold combination. Acta Orthop Traumatol Turc 2019;53:372-5. 